\title{
Intercomparison of solar UV direct irradiance spectral measurements at Izana in June 2005
}

\begin{abstract}
A. Bais, M. Blumthaler, A. Webb, G. Seckmeyer, S. Thiel, et al.
\end{abstract}

A. Bais, M. Blumthaler, A. Webb, G. Seckmeyer, S. Thiel, S. Kazadzis, A. Redondas, R. Kift, N. Kouremeti, B. Schallhart, R. Schmitt, D. Pisulla, J. P. Diaz, O. Garcia, A. M. Diaz Rodriguez, A. Smedley, "Intercomparison of solar UV direct irradiance spectral measurements at Izana in June 2005," Proc. SPIE 5886, Ultraviolet Ground- and Space-based Measurements, Models, and Effects V, 588609 (15 February 2007); doi: 10.1117/12.619925 


\title{
Intercomparison of solar UV direct irradiance spectral measurements at Izana in June 2005
}

\author{
A. Bais ${ }^{\mathrm{a}}$, M. Blumthaler ${ }^{\mathrm{b}}$, A. Webb ${ }^{\mathrm{c}}$, G. Seckmeyer ${ }^{\mathrm{d}}$, S. Thiel ${ }^{\mathrm{e}}$, S. Kazadzis ${ }^{\mathrm{a}}$, \\ A. Redondas ${ }^{\mathrm{f}}$, R. Kift ${ }^{\mathrm{c}}$, N. Kouremeti ${ }^{\mathrm{a}}$, B. Schallhart ${ }^{\mathrm{b}}$, R. Schmitt ${ }^{\mathrm{g}}$, D. Pisulla ${ }^{\mathrm{d}}$, \\ J. P. Diaz ${ }^{\mathrm{h}}$, O. Garcia ${ }^{\mathrm{h}}$, A. M. Diaz Rodriguez ${ }^{\mathrm{h}}$, A. Smedley ${ }^{\mathrm{c}}$ \\ ${ }^{a}$ Aristotle University, Physics Department, Thessaloniki, Greece \\ ${ }^{\mathrm{b}}$ University of Innsbruck, Austria \\ ${ }^{\mathrm{c} S c h o o l}$ of Earth Atmospheric and Environmental Sciences, University of Manchester, UK \\ ${ }^{\mathrm{d}}$ University of Hannover, Institute for Meteorology and Climatology, Hannover, Germany \\ ${ }^{\mathrm{e}}$ Forschungszentrum Karlsruhe GmbH, Garmisch-Partenkirchen, Germany \\ Instituto Nacional De Meteorología, Santa Cruz de Tenerife, Spain \\ ${ }^{\mathrm{g}}$ Meteorologie Consult Gmbh, Glashütten, Germany \\ ${ }^{\mathrm{h}}$ University La Laguna, Spain
}

\begin{abstract}
Spectral measurements of direct solar ultraviolet irradiance are very important for many applications in the field of atmospheric sciences. Despite its usefulness, few UV monitoring sites include such measurements in their regular observational programs. Standardization of measurement methodologies and calibration techniques is required in order to reach the quality standard of global irradiance measurements.

This study presents preliminary results from an intercomparison campaign of seven UV spectroradiometers of different types that took place at the high altitude site of Izana $\left(28.3^{\circ} \mathrm{N}, 16.5^{\circ} \mathrm{W}, 2367 \mathrm{~m}\right.$ above sea level), in Tenerife, Canary Islands in June 2005. The campaign is focused primarily on spectral measurements of direct solar irradiance. Among the objectives is to improve the quality of direct solar irradiance spectral measurements, through instrumental modifications and standardization of calibration techniques, as well as to assess the significance of the differences in the field of view of the spectroradiometers with respect to aerosols and to solar zenith angle. Under the low aerosol conditions prevailing during this campaign, we aimed to establish the differences among the various instruments under "ideal" conditions. Moreover, continuous measurements under stable total ozone and aerosol optical depth will be used to determine the extraterrestrial solar flux, through the application of the Langley extrapolation method. A first comparison of sky radiance measurements of the zenith light and of various directions on the sky show effects of sensitivity to polarization of one type of instruments and the variability of the provisional radiance calibration of 4 instruments.
\end{abstract}

Keywords: UV Radiation, Direct, Solar UV irradiance

Ultraviolet Ground- and Space-based Measurements, Models, and Effects V,

edited by G. Bernhard, J. R. Slusser, J. R. Herman, W. Gao, Proc. of SPIE Vol. 5886

(SPIE, Bellingham, WA, 2005) $\cdot 0277-786$ X/05/\$15 $\cdot$ doi: 10.1117/12.619925

Proc. of SPIE 588609-1 


\section{INTRODUCTION}

Measurements of solar ultraviolet radiation reaching the earth's surface became very important during the last few years as both observations and predictions suggest a tendency for increasing UV levels, following the observed ozone decreases. Until now most of the technological effort has been put into global irradiance measurements and thus most of the present UV-related studies were based on such types of measurements. However, it is well known that other types of measurements, such as the direct and actinic flux, are also important for specific research topics. During the last decade there is an increasing activity about these types of measurements, due to their significant applications in both the Atmospheric Sciences and the Biology communities.

Spectral measurements of direct solar ultraviolet irradiance are very important for many applications in the field of atmospheric sciences. They are useful for the determination of the aerosol optical depth, as well as of the of the column abundance of atmospheric species absorbing in the ultraviolet [Huber et al., 1995; Huber et al., 1996; Mayer and Seckmeyer, 1998]. Modeling studies can greatly benefit from such measurements, since its parameterization is much easier than that of the global or the diffuse radiation. Finally, they can be used to determine the spectrum of the extraterrestrial (ET) solar flux from ground-based measurements, with the Langley extrapolation method.

Despite its usefulness, spectral measurements of the direct solar ultraviolet irradiance have been only recently included in the observational programs of a few UV spectroradiometers (e.g. [Bais, 1997; Huber et al., 1996]). The first reason for this delay was the need for a pointing system, to direct the beam light of the sun into the spectrometer, which would be also adaptable to the already existing instruments. This problem was finally solved, mainly after the wide use of fibers in UV spectroradiometry. The second reason was the difficulty to establish a reliable methodology for the absolute calibration of the direct solar irradiance. Although significant improvements have been made during the last years, some of the uncertainties in the calibration and measurements methodology have not been eliminated yet.

The knowledge of the spectral solar ultraviolet irradiance reaching the top of the earth's atmosphere is of fundamental importance for the correct interpretation of phenomena related to the propagation of the solar radiance through the earth's atmosphere. In addition, model calculations, that are used to simulate spectral UV measurements in the atmosphere, depend strongly on the accuracy of the extraterrestrial solar spectrum. For this purpose, various experiments and scientific missions (including satellite, rocket and balloon measurements) were carried out during the last 20 years, aiming at the absolute determination of the solar spectrum outside the earth's atmosphere. The advantage of the solar spectra measurements from the space, is the absence of all the atmospheric processes that modify the radiation field reaching the ground, the effect of which is in principle difficult to be removed. On the other hand, however, there is no direct control on the instrumentation used during these missions, and in many cases post-mission analysis and corrections of the data are necessary to derive reliable results.

[Neckel and Labs, 1983] calculated the solar spectral irradiance in the region $330-400 \mathrm{~nm}$, in $1 \mathrm{~nm}$ intervals, from ground-based observations at Jungfraujoch (3.6 km altitude) looking at the center of the solar disk. In 1983 and 1985 detailed high resolution ET spectra in the ultraviolet were measured by the SOLSPEC and SUSIM instruments on board Spacelab 1 and 2 respectively ([Labs et al., 1987; Vanhoosier et al., 1988]. [Nicolet, 1989] showed that the spectra obtained at these two missions agree within $\pm 5 \%$ in the 300 - $325 \mathrm{~nm}$ region, while larger differences were found at higher wavelengths. More recently, in the 1990's, there were two major satellite experiments with the aim to measure the spectrum of solar ultraviolet irradiance outside the earth's atmosphere. The first experiment comprised a series of three Spacelab missions in 1992, 1993 and 1994, under the name Atmospheric Laboratory for Applications and Science (ATLAS) [Kaye and Miller, 1996]. Another series of solar ultraviolet spectral irradiance measurements were obtained during the two Upper Atmosphere Research Satellite (UARS) missions. [Woods et al., 1996] reported that the measurements of the four instruments of the ATLAS and UARS missions agree to within the $2 \sigma$ uncertainty of any instrument, which is about 5 to $10 \%$ for all wavelengths above $160 \mathrm{~nm}$. Also a comparison of the mean ATLAS-1 spectrum with the mean UARS spectrum, as $5 \mathrm{~nm}$ averages, showed discrepancies within $\pm 3 \%$, without particular spectral bias.

Although there has been large improvement in the accuracy of the solar spectra obtained by space-borne instruments during late 1980's and the 1990's, there are still considerable uncertainties in these measurements at the ultraviolet wavelengths. Continuous comparisons and validations of these data will help in determining their absolute level of accuracy and investigate their weaknesses. Ground-based measurements can be useful in assessing the absolute 
accuracy and the wavelength stability of the space-derived solar spectra, especially when more that one instruments, independently calibrated, are used at the same time.

This study focuses on the presentation and preliminary analysis of direct spectral irradiance and spectral radiance measurements performed during a dedicated for this purpose experimental campaign. The collected data would help to understand the differences between the participating instruments and to improve their quality through instrument modifications and standardization of calibration techniques. A second objective was to assess the influence of the different field of view of the spectroradiometers to direct irradiance with respect to aerosol amounts and to solar zenith angle (sza). The low aerosol amounts that usually prevail at this site would help to establish the differences amongst the various instruments under almost ideal conditions. Finally, continuous measurements under stable total ozone and aerosol optical depth would allow the determination of the extraterrestrial solar flux, through the application of the Langley extrapolation method. Simultaneous retrieval of the extraterrestrial solar flux by several spectroradiometers is expected to reduce the experimental uncertainties and increase the credibility of the results.

\section{LOCATION AND INSTRUMENTATION}

The campaign took place at the high altitude Meteorological Observatory of Izana $\left(28.3^{\circ} \mathrm{N}, 16.5^{\circ} \mathrm{W}, 2367 \mathrm{~m}\right.$ above sea level), in Tenerife, Spain between 3 and 13 June 2005. The Island of Tenerife, is located roughly $300 \mathrm{~km}$ west of the African coast, therefore is usually affected by dust transported from Sahara. The observatory is situated on a mountain platform, $15 \mathrm{~km}$ north-east of the volcano Teide (3718 $\mathrm{m}$ a.s.l.). The local wind field at the site is dominated by northwesterly winds. A predominant meteorological attribute of the Canary Islands region is the presence of the trade wind inversion that persists through most of the year and is well below the altitude of the station. The ground in the vicinity around Izaña is loosely covered with light volcanic soil. The vegetation in the surrounding area is sparse, consisting mainly of broom. The location is considered ideal for UV intercomparison purposes and several calibration and intercomparison campaigns have been organized for the last decade.

TABLE 1: List of instruments that took part in the Izana campaign, some of their main technical characteristics and the calibration methodologies used

\begin{tabular}{|c|c|c|c|c|c|}
\hline $\begin{array}{l}\text { Institute / Instrument } \\
\text { ID }\end{array}$ & Instrument type & $\begin{array}{l}\text { Spectral } \\
\text { range }(\mathrm{nm})\end{array}$ & $\begin{array}{l}\text { Direct optics } \\
\text { field of view }\end{array}$ & $\begin{array}{l}\text { FWHM } \\
(\mathbf{n m})\end{array}$ & Calibration method \\
\hline $\begin{array}{l}\text { Medical U. of } \\
\text { Innsbruck }\end{array}$ & Bentham DTM 300 & $280-600$ & $1.5^{\circ}$ & 0.52 & $\begin{array}{l}\text { PTB } 1000 \mathrm{~W} \text { FEL at } 2 \mathrm{~m} \\
\text { distance }\end{array}$ \\
\hline $\begin{array}{l}\text { Forschungszentrum } \\
\text { Karlsruhe GmbH }\end{array}$ & Bentham DTM 300 & $200-1100$ & $2.4^{\circ}$ & 0.96 & PTB 1000W FEL \\
\hline $\begin{array}{l}\text { Aristotle U. of } \\
\text { Thessaloniki }\end{array}$ & Brewer MKIII & $290-365$ & $2.2^{\circ}$ & 0.52 & $\begin{array}{l}\text { Measurement of Direct- } \\
\text { Diffuse with shadow disk }\end{array}$ \\
\hline $\begin{array}{l}\text { Aristotle U. of } \\
\text { Thessaloniki }\end{array}$ & $\begin{array}{l}\text { METCON MS-CCD } \\
\text { image spectrometer }\end{array}$ & $280-1000$ & $1.2^{\circ}$ & 1.37 & $\begin{array}{l}\text { PTB } 1000 \mathrm{~W} \text { DXW at } 3.5 \mathrm{~m} \\
\text { distance }\end{array}$ \\
\hline $\begin{array}{l}\text { University of } \\
\text { Manchester }\end{array}$ & Bentham DTM 300 & $280-600$ & $0.96^{\circ}$ & 2.26 & $\begin{array}{l}\text { NIST 1000W FEL at } 4 \mathrm{~m} \\
\text { distance }\end{array}$ \\
\hline $\begin{array}{l}\text { University of } \\
\text { Manchester }\end{array}$ & $\begin{array}{l}\text { METCON } \\
\text { Photodiode Array }\end{array}$ & $280-700$ & $2.7^{\circ}$ & 2.26 & $\begin{array}{l}\text { NIST 1000W FEL at } 4 \mathrm{~m} \\
\text { distance }\end{array}$ \\
\hline University of Hannover & Bentham TMC 300 & $280-600$ & $4.5^{\circ}$ & 0.92 & PTB 1000W FEL \\
\hline $\begin{array}{l}\text { University of La } \\
\text { Laguna }\end{array}$ & Optronic 752 & $250-800$ & $1.5^{\circ}$ & 1.65 & Langley extrapolation \\
\hline INM, Spain & Brewer MKIII & $290-365$ & $1.5^{\circ}$ & 0.58 & $\begin{array}{l}\text { Measurement of Direct- } \\
\text { Diffuse with shadow disk }\end{array}$ \\
\hline INM, Spain & Brewer MKIII & $290-365$ & $1.5^{\circ}$ & 0.58 & $\begin{array}{l}\text { Measurement of Direct- } \\
\text { Diffuse with shadow disk }\end{array}$ \\
\hline
\end{tabular}


Ten UV spectroradiometers took place, each equipped with different type of entrance optics to collect direct irradiance and radiance. The primary focus of the campaign was measurements of spectral direct solar irradiance. Table 1 lists the participating instruments and some of their main technical characteristics.

A series of tasks were performed for addressing the objectives of the campaign, which are summarized below:

Task 1: Synchronized measurements of direct spectral irradiance from sunset to sunrise every 20 minutes for absolute comparisons between instruments and for Langley extrapolations. (Spectral range: $290-450 \mathrm{~nm}$ in steps of $0.5 \mathrm{~nm}$, Synchronization at $3 \mathrm{sec}$ per wavelength step)

Task 2: Unsynchronized scans of direct spectral irradiance from sunset to sunrise covering the entire operational wavelength range for each instrument, to be used also for absolute comparisons and for Langley extrapolations.

Task 3: Measurement of zenith radiance at $340 \mathrm{~nm}$ from $0^{\circ}-360^{\circ}$ azimuth angle in steps of $30^{\circ}$, for checking the sensitivity of the instruments to polarization of incoming radiation. The azimuth angles were relative to the Sun's azimuth.

Task 4: Synchronized measurements of spectral radiance at selected directions for comparison of the absolute calibration of the instruments. (Spectral range: $290-600 \mathrm{~nm}$ in steps of $0.5 \mathrm{~nm}$, Synchronization at $2 \mathrm{sec}$ per wavelength step)

Task 5: Mapping of sky radiance at 500, 400, 350,320,305nm, at a predefined set of directions, covering half hemisphere at one side of the Sun's meridian.

Task 6: Sky radiance measurements at $350 \mathrm{~nm}$ near the sun. This task aimed at investigating how each instrument could sense the variation of the radiance as the direction of the measurement was approaching the sun's direction.

All these tasks were attempted by all instruments during the 10 days of the campaign. Most of the instruments were capable in performing these tasks. However, some of the datasets were not timely available and therefore in this study we present results from the available data only, some of which are still considered as preliminary. This is also the reason for not identifying all instruments in the comparisons that follow.

All spectral measurements (both direct irradiance and radiance) were standardized to a common spectral resolution of 1 $\mathrm{nm}$ FWHM in order to eliminate the effects of the different slit functions of the instruments. This was done with the SHICrivm algorithm [Slaper et al., 1995]. The same algorithm corrects the spectra for possible wavelength shifts.

\section{COMPARISONS OF DIRECT SPECTRAL IRRADIANCES}

During June 5 and 11, 2005 all instruments followed task 1 and measured the direct spectral irradiance covering a solar zenith angle range from about $80^{\circ}$ to $6^{\circ}$. The ATI instrument was chosen as a reference for comparison, because it was one of the few instruments that regularly performed such measurements in the past and because its wavelength range was sufficiently long to be compared with all other instruments.

Figure 1, presents ratios of spectral direct irradiances measured by each instrument against the measurement of the ATI instrument at two selected wavelengths $(320 \pm 2.5 \mathrm{~nm}$ and $360 \pm 2.5 \mathrm{~nm})$, during both days. Despite the differences in the calibration methodologies, measurement principles, field of view of input optics and calibration lamp differences, almost all instruments agree within $\pm 10 \%$ for solar zenith angles smaller than $70^{\circ}$, while for higher solar zenith angles the differences become occasionally larger. For some instruments (I2, I5 and I6) there is a distinct solar zenith angle dependency which can be partly attributed to larger field of view with respect to the field of view of the comparison reference instrument. For example, the instrument I2 (with a field of view of 4.5 degrees) measures higher on large solar zenith angles, and the differences become smaller at the longest wavelength. An instrument with larger field of view is expected to get additional radiation from scattering (both Rayleigh and Mie) and therefore to overestimate the measured direct irradiance, especially at larger solar zenith angles when the proportion of scattered radiation to direct irradiance becomes larger. As scattering is less efficient at higher wavelength this effect becomes smaller at the UV-A. 

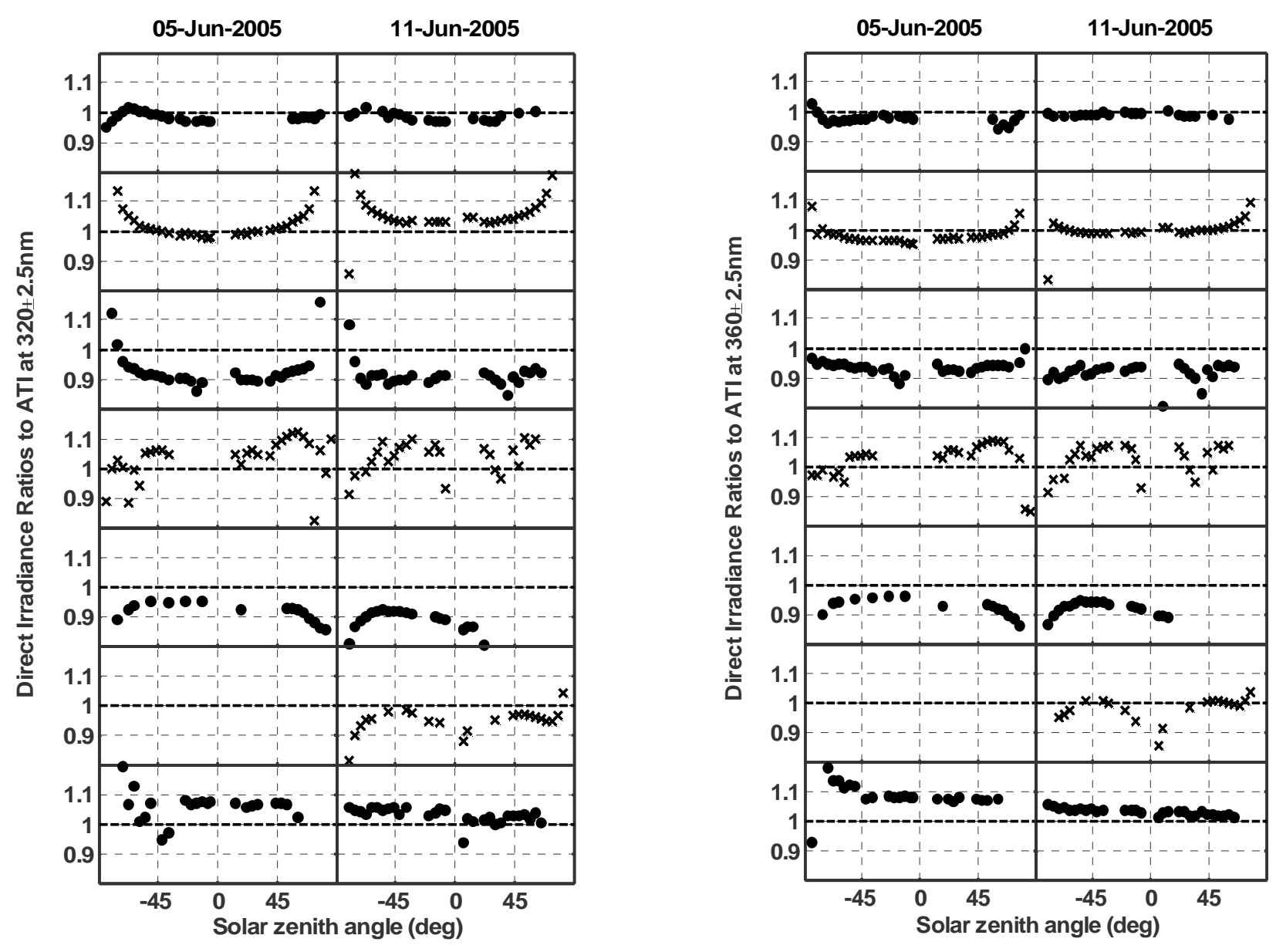

Figure 1. Ratios of direct spectral irradiance measured from all instruments, denoted as I1 to I7 starting from top, to ATI at $320 \pm 2.5$ (left) and $360 \pm 2.5$ (right) for two days of the campaign

It is encouraging that the calibration techniques followed by different instruments do not influence significantly the comparison. For example, the I1 measurements, which is calibrated using quasi simultaneous measurements of global, direct and the diffuse irradiance with the aid of a shadowing disk, agree within $\pm 5 \%$ over all solar angles with ATI, which is calibrated using a lamp positioned at $4 \mathrm{~m}$. In this particular instrument sensitivity to solar zenith angle was discovered, which is discussed separately in Section 3.1. The instruments I3 and I4 are on the average different by $-8 \%$ and 5\% respectively, without any particular solar zenith angle dependency. These differences could be attributed to the differences in the calibration standards or the calibration principles and techniques that they use. For I7 the absolute level of the comparison changes between 5 and 11 June, suggests changes in the absolute sensitivity of the instrument that were not detected and corrected during the campaign.

\subsection{Brewer window polarization effect}

In the Brewer spectroradiometers the direct solar irradiance and radiance are collected by directing a rotating prism towards the sun (or to a specific direction at the sly in case radiance is measured). The incoming radiation passes through a tilted quartz window which is used for allowing the unattended operation of the instrument under rainy conditions.

[Cede et al., 2003] investigated in the laboratory the effects of this window on the direct irradiance measurements due to polarization. And reported two major sources for the sensitivity to polarization: (a) The flat quartz plate as the first optical element alters the polarization state of the transmitted light by Fresnel reflection at oblique incident angles, and 
(b) the internal grating produces almost $100 \%$ polarization of the incident light perpendicular to the direction of the ruled grating. The combination of both effects results in a zenith angle dependence of the instrument's sensitivity to the incoming un-polarized radiation, such as that measured directly from the Sun. Thus the Brewer is $2 \%$ more sensitive to radiation incident from solar zenith angle of $0^{\circ}$ and $10 \%$ less sensitive at solar zenith angle of $80^{\circ}$ with respect to normal incidence $\left(35^{\circ}\right)$. Since the solar zenith angle dependence is independent of wavelength this effect cancels out when calculating wavelength-ratios, as used for total ozone retrievals.

For the Brewer MKIII operating at Thessaloniki this effect was investigated by measuring the direct spectral irradiance at $320 \mathrm{~nm}$ with and without the front window of the instrument for a range of solar zenith angles. Each measurement without the window was preceded and followed by a measurement through the window, which were averaged to account for the effect of small changes in sza. Each measurement through the window was divided by the corresponding one without the window and this ratio was normalized to the ratio measured at sza of $35^{\circ}$ (normal incidence of radiation on the window). The variation of this ratio as a function of sza is shown in the lower panel of Figure 2. The solid curves in the this figure is a combination of a linear and a polynomial fit, which describe sufficiently the variation of the ratio, and can be used to correct the direct spectral measurements of the Brewer. The correction factor is less than $2 \%$ for solar zenith angles smaller than 650 , reaching $5 \%$ and $10 \%$ respectively at $75^{\circ}$ and $80^{\circ}$.

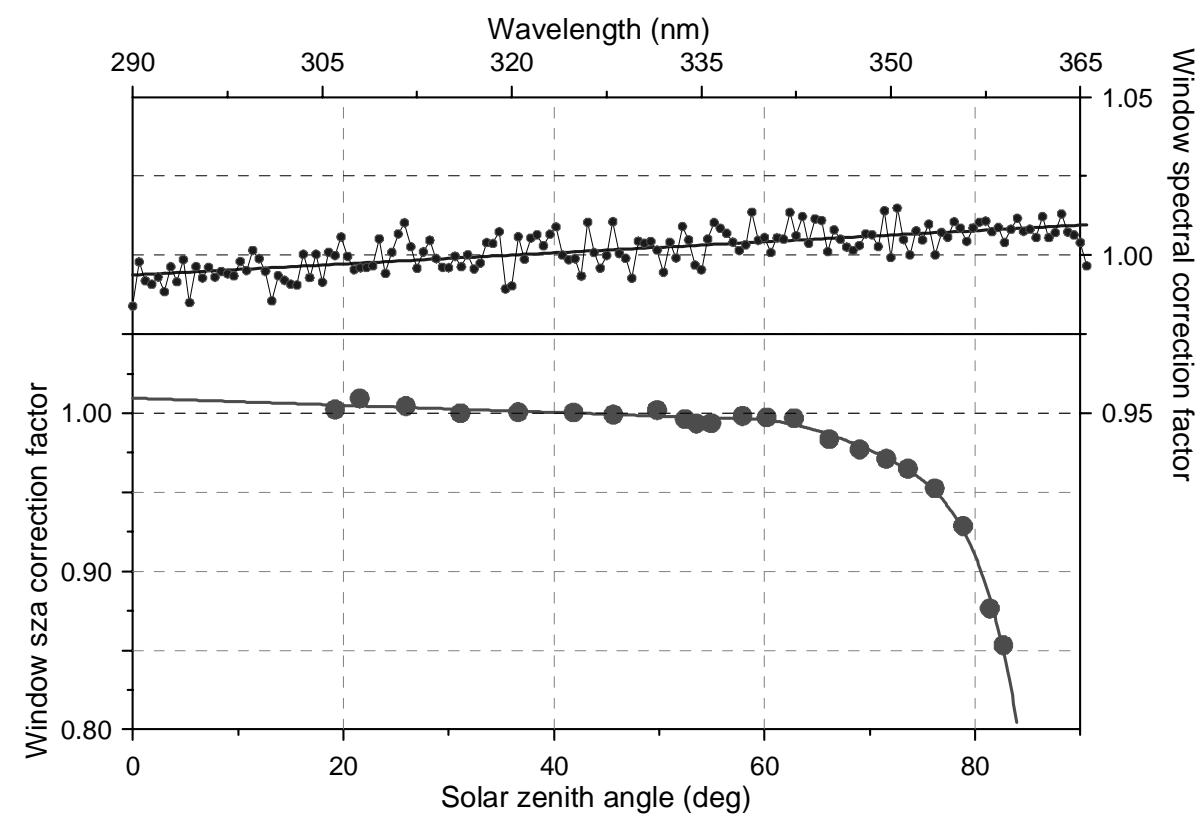

Figure 2: Spectral dependence of the ratio of direct irradiances measured in the laboratory without and through the side window of the Brewer spectroradiometer. (Upper panel) Solar zenith angle dependence of the same ratio at $320 \mathrm{~nm}$ (Lower panel). The solid curves are fits on the data that are used for determining correction factors for the window effect on the spectral direct irradiance measurements.

The same ratio was measured also in the laboratory using a $1000 \mathrm{~W}$ lamp as source for only one angle of incidence but for the entire operational wavelength range of the instrument in order to determine any spectral effects of the window. The upper panel of Figure 2 illustrates this effect which is about $1.5 \%$ between 290 and $366 \mathrm{~nm}$ and can be represented by a linear fit, which is normalized at $320 \mathrm{~nm}$ where the window effect as a function of sza was measured.

These corrections were applied to the direct irradiance spectral measurements performed during the campaign and the result is evident from Figure 3, which shows the ratio of spectral irradiance measured by the GRT and ATI instruments at two wavelengths before (left panels) and after (right panels) the application of the correction. Apparently, the diurnal variation of the ratio which follows the variation of sza is diminished when the corrected for the window effect data are used. 


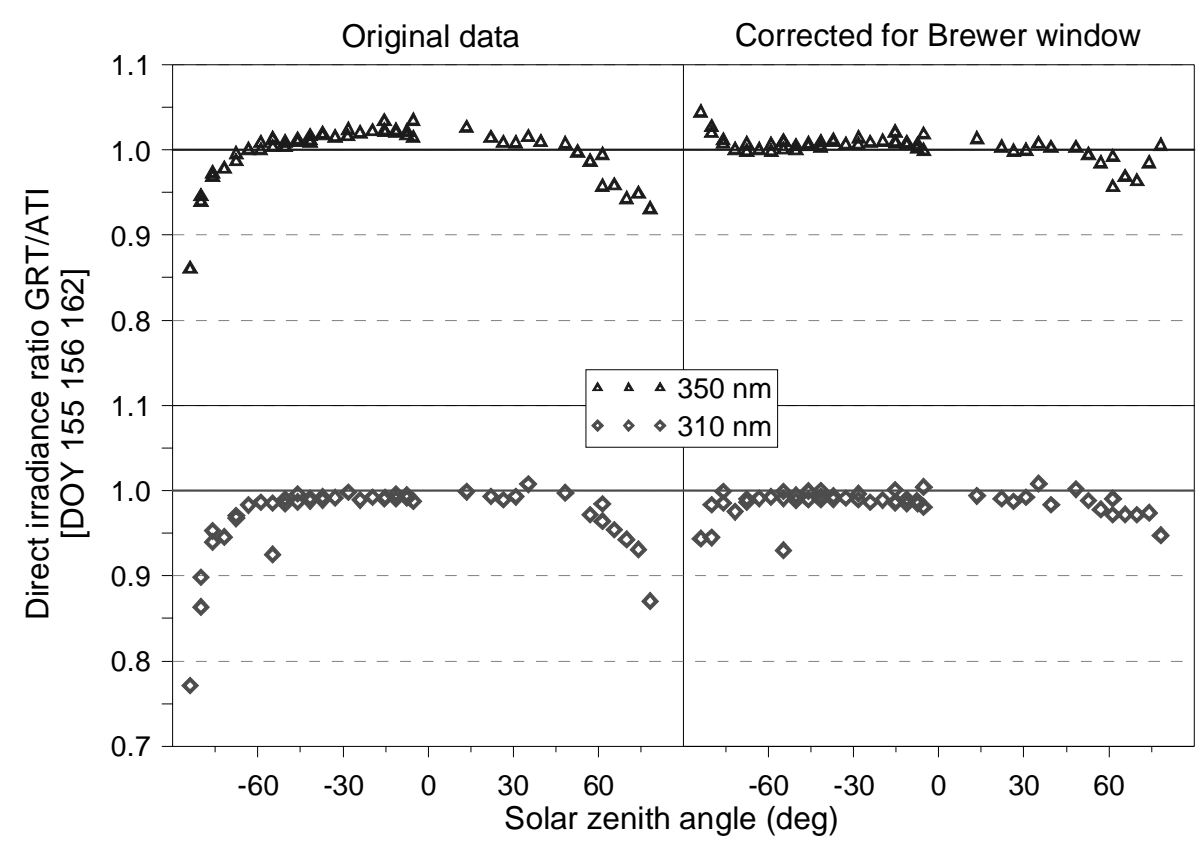

Figure 3: Diurnal variation of the direct irradiance ratio measured at $350 \mathrm{~nm}$ (Upper part) and at $310 \mathrm{~nm}$ (Lower part) by GRT and ATI instruments before (Left panels) and after the application of correction for the window effect (Right panels).

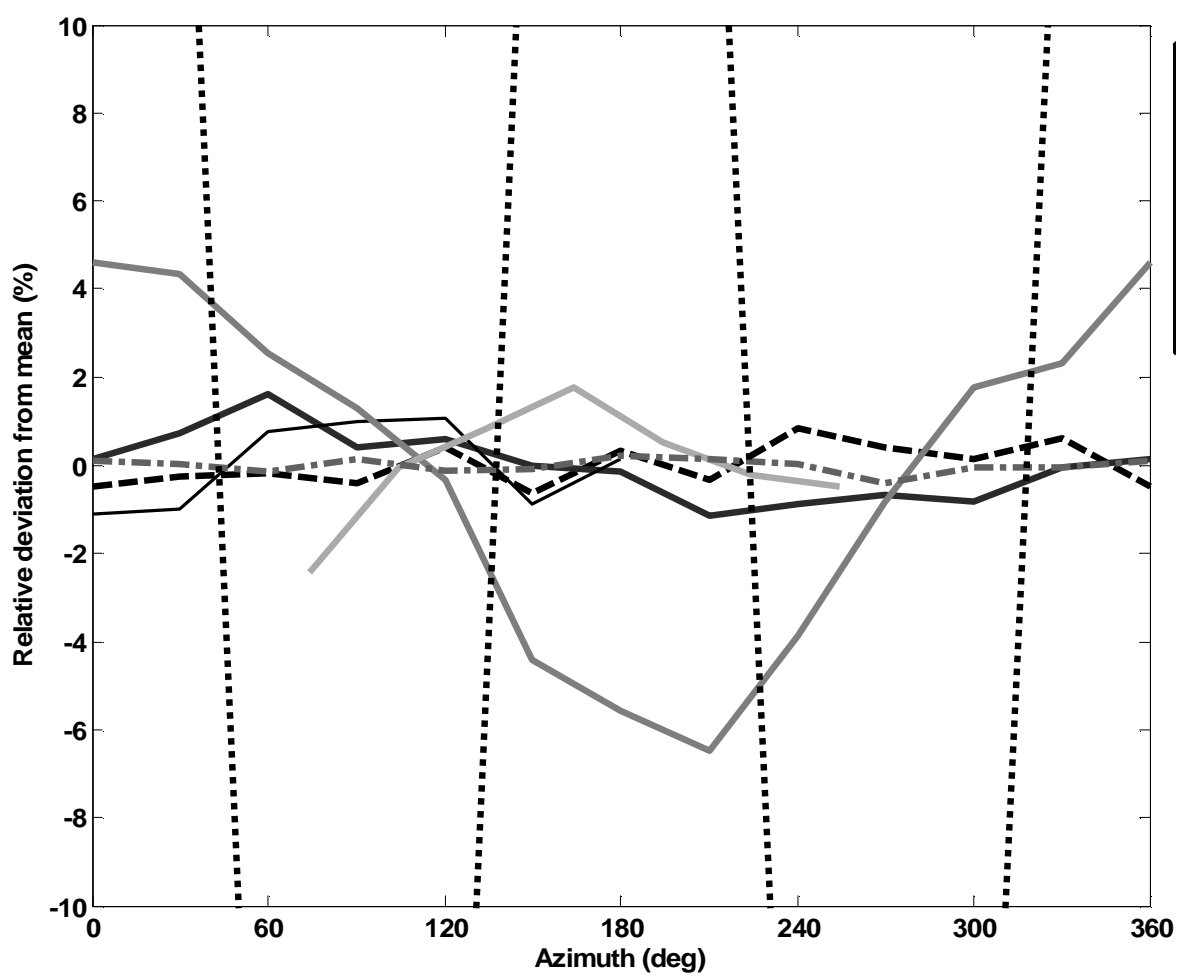

Figure 4. Measurements of radiance from the zenith at $340 \mathrm{~nm}$ and at azimuth angles between $0^{\circ}$ and $360^{\circ}$. The measurements of each instrument are normalized to their average and corrected for changes in radiance during the period of measurements. Each line represents a different instrument. The dotted lines that deviate by more than $\pm 10 \%$ are measurements from a Brewer. 
Similar diurnal behavior in the ratio to ATI instrument present also the other two Brewers that participated in the campaign, but no corrections were applied because the appropriate correction factors were not determined yet for these instruments.

\section{SPECTRAL RADIANCE MEASUREMENTS}

\subsection{Radiance from the zenith}

The aim of this task was to perform measurements of the radiance at the zenith by turning the input optics $360^{\circ}$ in azimuth, in order to check the sensitivity of the instruments to polarization, since the light from the zenith is polarized. The results of the measurements are shown in Figure 4, as relative changes of the radiance at different azimuths from the mean of all measurements. To account for slight changes in the zenith radiation during the period of the measurements due to changing solar zenith angle, the first and the last point of the measurements was taken at the same azimuth and all measurements were corrected assuming linear change of the radiation filed from the beginning to the end of the measurements schedule. The Brewer instrument has a known problem with polarization [Webb et al., 2002] and therefore the variation of its sensitivity by about $\pm 50 \%$ is not a surprising result. All other instruments were proved to be almost insensitive to polarization with deviations of less than $\pm 2 \%$, except from one instrument that showed a peculiar behavior with deviations of up to $\pm 5 \%$, which cannot be attributed to polarization. The reasons for this behavior have not been yet identified. This task is considered very essential for assessing the behavior of the different instruments when measuring the spectral radiance from other directions in the sky.

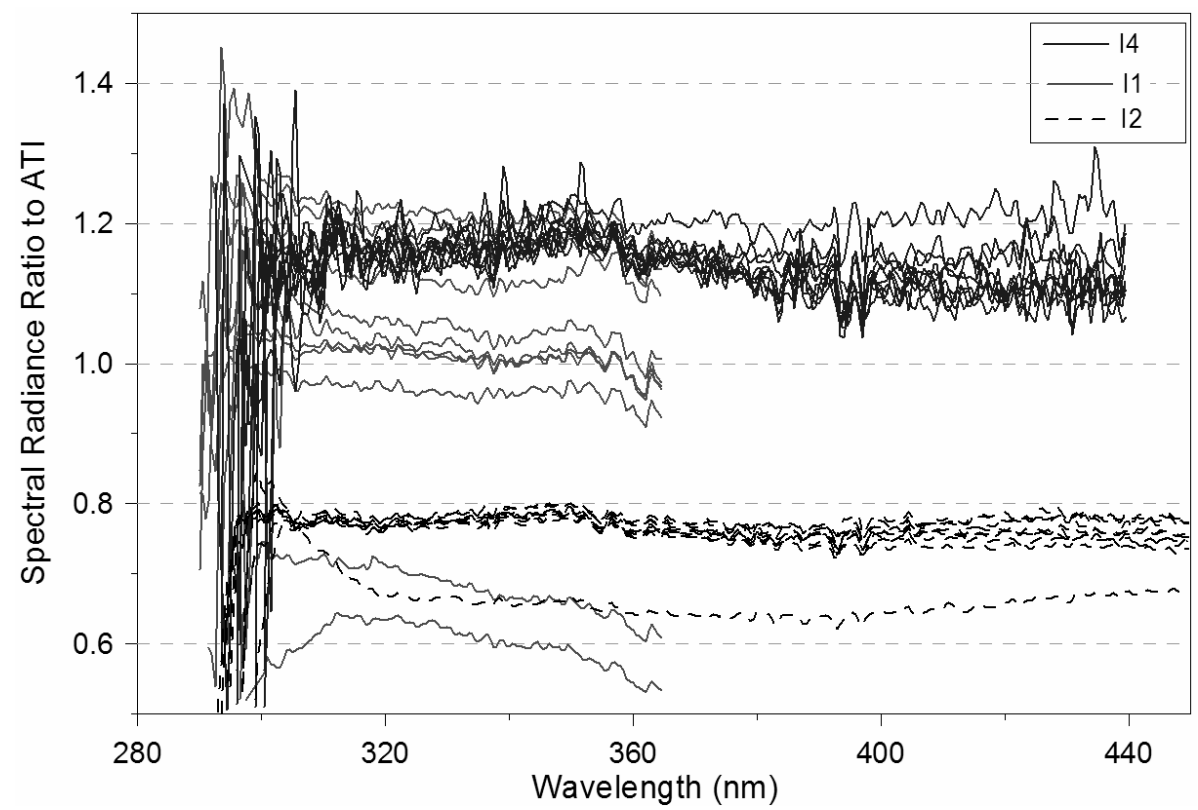

Figure 5: Ratio of radiance spectral measurements recorded by three instruments (I1, I2 and I4) to ATI from different directions as a function of wavelength.

\subsection{Spectral radiance at different directions}

Spectral measurements at 6 appointed positions (in azimuth and zenith angle) on the sky were carried out synchronously by four spectroradiometers. Each position was measured twice to check reproducibility. The ratios of these radiance spectra relative to ATI are shown in Figure 5. Most ratios of instruments I2 and I4 to ATI are flat with wavelength and lay within about 5\%, however, one is about $20 \%$ higher than ATI and one is about $20 \%$ lower. These absolute differences are only provisional, because recalibration of the radiance input optics in the laboratory of the individual institutes will be carried out after the field campaign. The ratio of the third instrument (I1) relative to ATI is very different for the different positions on the sky, this is a Brewer instrument, and it suffers, as already discussed in 4.1, from sensitivity to polarization. 


\section{LANGLEY EXTRAPOLATIONS}

One of the main tasks of the campaign was the use of direct irradiance spectra to make Langley plots, in order to determine the extraterrestrial solar irradiance spectrum in the operation range of the instruments. For Langley extrapolations it is necessary that stable conditions prevail over the period of the measurements. For the UV area the most important parameters that must be stable are the ozone and the aerosol optical depth. Unfortunately both these parameters were not very stable during the campaign, exhibiting notable variability during the day. As it concerns total ozone, this is measured by the Brewer instruments and can be also determined from the ATI instrument following the methodology by [Huber et al., 1995], and thus can be removed from the logarithms of the irradiance that is used in the Langley plots. The same can be done for the effect of Rayleigh scattering, which is proportional to the atmospheric pressure. Although the analysis of the results for both instruments is ongoing, we present here the first extraterrestrial spectra that were produced by GRT and ATI instruments respectively on days 162 and 153, together with the ATLAS 3 spectrum that is convoluted with the slit function of GRT (0.55 nm FWHM). The resolution for ATI is $1 \mathrm{~nm}$ FWHM as data that were standardized by the SCICrivm algorithm were used.



Figure 6: Extraterrestrial solar irradiance spectra derived from Langley extrapolation plots of surface direct irradiance spectra by the ATI and GRT instruments at two different days (153 and 162 of 2005).

The agreement between the three spectra is good, within a few percent down to about $300 \mathrm{~nm}$, and becomes worse at lower wavelengths, mainly due to uncertainties in removing the effect of total ozone. The analysis is continued with the inclusion of more days.

\section{CONCLUSIONS}

Preliminary results from the experimental campaign that took place in Izana Tenerife in June 2005 are presented. The comparisons of direct irradiance spectra recorded by seven of the participated instruments are sufficiently good, taking into account that most of the instruments were compared for the first time. In general the agreement was to within \pm 10 $\%$ while in few cases even better agreements were achieved. 
A sensitivity of the flat window of the Brewer to the incident angle of direct solar irradiance was investigated and correction function was determined which improved significantly the comparison with the ATI instrument.

The spectra radiances spectra were preliminary as absolute calibrations were not applied yet to the data available for this study. It is encouraging that ratios of 12 spectra between instruments are repeatable, except from those of the Brewer spectroradiometer due to the know problem in sensitivity to polarized light.

The first results of Langley derived extraterrestrial spectra from two instruments are also good.

\section{ACKNOWLEDGMENTS:}

We would like to thank WMO for providing partial financial support for the campaign as well as the director of the Izana Observatory, Dr. Emilio Cuevas for providing the facilities that hosted the campaign.

\section{REFERENCES}

1. $\quad$ Bais, A.F., Absolute Spectral Measurements of Direct Solar Ultraviolet Irradiance with a Brewer Spectrophotometer, Applied Optics, 20 (07), 5199-5204, 1997.

2. $\quad$ Cede, A., G. Labow, M. Kowalewski, N. Krotkov, and O. Dubovik, Deriving aerosol parameters from absolute UV sky radiance measurements using a Brewer double spectrometer, in Ultraviolet Ground- and Space-based measurements, Models, and Effects III, edited by J.R. Slusser, J.R. Herman, and W. Gao, pp. 323-329, SPIE-The International Society for Optical Engineering, San Diego, USA, 2003.

3. Huber, M., M. Blumthaler, W. Ambach, and J. Staehelin, Total atmospheric ozone determined from spectral measurements of direct solar UV irradiance, Geophysical Research Letters, 22 (1), 53-56, 1995.

4. Kaye, J.A., and T.L. Miller, The ATLAS series of shuttle missions, Geophys. Res. Lett., 23 (17), 2285-2288, 1996.

5. Labs, D., H. Neckel, P.C. Simon, and G. Thuillier, Ultraviolet Solar Irradiance Measurement from 200 to 358 nm during Spacelab 1 Mission, Solar Physics, 107, 203-219, 1987.

6. Mayer, B., and G. Seckmeyer, Retrieving ozone columns from spectral direct and global UV irradiance measurements, in Proceedings of the XVIII Quadrennial Ozone Symposium, edited by G. Visconti, pp. 935938, Parco Scientifico e Technologico d'Abruzzio, L'Aquila, Italy, 1998.

7. Neckel, H., and D. Labs, The Solar Radiation Between 3300 and 12500 A, Solar Physics, 90, 205-258, 1983.

8. Nicolet, M., Solar spectral irradiances with their diversity between 120 and $900 \mathrm{~nm}$, Planetary and Space Science, 37 (10), 1249-1289, 1989.

9. Slaper, H., H.A.J.M. Reinen, M. Blumthaler, M. Huber, and F. Kuik, Comparing ground-level spectrally resolved solar UV measurements using various instruments: a technique resolving effects of wavelength shift and slit width, Geophysical Research Letters, 22 (20), 2721-2724, 1995.

10. Vanhoosier, M.E., J.D. Bartoe, G.E. Brueckner, D.K. Prinz, and E.O. Hulburt, Absolute Solar Spectral Irradiance $120 \mathrm{~nm}-400 \mathrm{~nm}$ (Results from the Solar Ultraviolet Spectral Irradiance Monitor - SUSIMExperiment on Space Board Spacelab 2), Astro. Lett. and Communications, 27, 163-168, 1988.

11. Webb, A.R., A.F. Bais, M. Blumthaler, G.P. Gobbi, A. Kylling, R. Schmitt, S. Thiel, F. Barnaba, T. Danielsen, W. Junkermann, A. Kazantzidis, P. Kelly, R. Kift, G.L. Liberti, M. Misslbeck, B. Schallhart, J. Schreder, and C. Topaloglou, Measuring spectral actinic flux and irradiance: Experimental results from the Actinic Flux Determination from Measurements of Irradiance (ADMIRA) project, Journal of Atmospheric and Oceanic Technology, 19 (7), 1049-1062, 2002.

12. Woods, T.N., D.K. Prinz, G.J. Rottman, J. London, P.C. Crane, R.P. Cebula, E. Hilsenrath, G.E. Brueckner, M.D. Andrews, O.R. White, M.E. VanHoosier, L.E. Floyd, L.C. Herring, B.G. Knapp, C.K. Pankratz, and P. A. Reiser, Validation of the UARS solar ultraviolet irradiances: Comparison with the ATLAS 1 and 2 measurements, J. Geophys. Res, 101 (D6), 9541-9569, 1996. 